\title{
Effect of Maternal Employment on Infant Feeding Practices in Southwestern Nigeria
}

\author{
Beatrice Olubukola Ogunba \\ Department of Family, Nutrition and Consumer Sciences, Faculty of Agriculture, Obafemi Awolowo University, \\ Ile Ife, Nigeria \\ Email: ogunbabeatrice@yahoo.com
}

Received 13 January 2015; accepted 30 April 2015; published 4 May 2015

Copyright (C) 2015 by author and Scientific Research Publishing Inc. This work is licensed under the Creative Commons Attribution International License (CC BY). http://creativecommons.org/licenses/by/4.0/

(c) (i) Open Access

\section{Abstract}

The study investigated the effect of maternal employment on breastfeeding and child care practices of mothers in Southwestern Nigeria. Information was collected on maternal socio economic characteristics, care and feeding practices of $\mathbf{4 5 0}$ mothers selected by multi stage random sampling procedure from both urban and rural communities. Results revealed that $46.9 \%$ mothers spent more than 8 hours at work, $62.7 \%$ worked outside their homes and $73.1 \%$ spent about 17 24 hours with their children per day. Children received prelacteal feeds such as water $(61.1 \%)$, concoction (34\%), glucose (32\%) and infant formula (54.7\%). Mean number of breastfeeding per day was $9.7 \pm 3.9$; only $24 \%$ were exclusively breastfed, $37.3 \%$ introduced complementary foods at 6 months and 68.6\% terminated breastfeeding between $13-18$ months. Mothers that were engaged in work outside their home in offices and factories practiced exclusive breastfeeding. Mothers below 30 years of age used prelacteal feeds, did not practice exclusive breastfeeding (58.3\%), terminated breastfeeding earlier and combined the use of feeding bottles, plates and cups for feeding $(50.3 \%)$ when compared with mothers between 40 - 50 years. Mothers in the rural areas used water as prelacteal feeds $(85.3 \%)$ mothers in urban communities used infant formula (65.4\%). A significant association was found between maternal places of employment. It is strongly associated with the timing of introduction of complementary foods $(p<0.02)$ and the number of snack consumed/day $(p<0.03)$. Conclusively, maternal place of work positively influences the adoption of appropriate infant feeding practice. Working mothers should receive more support in the work place for them to practice appropriate feeding practices.

\section{Keywords}

Feeding Practices, Mothers, Work and Malnutrition 


\section{Introduction}

In Nigeria mothers rarely follow the appropriate infant feeding recommendations. Infants were given prelacteal feeds such as water to "welcome the child to the world" while others received concoctions to "wash off all the dirt accumulated in the stomach of the new born after delivery". Glucose is one of the prelacteal feeds given to infant as mothers await the let down of breast milk from the mammary gland. Prelacteal feeding is a major barrier to exclusive breastfeeding [1] [2]. Only about $17 \%$ of children under six months are exclusively breastfed and more than half of children receive water in addition to breast milk in the first three months of life [3]. According to a study in UK working mothers were less likely to initiate and continue breastfeeding as they prefer infant formula [4]. Bottle-feeding is routinely used to provide supplements, glucose and infant formula to breastfed infants. Supplemental formula feeding is strongly associated with early breastfeeding termination. These inappropriate feeding behaviours are an important determinant of malnutrition [5]. In Nigeria 41\% of children under five are stunted, and it is more common in rural areas (45\%) than urban areas (31\%). Wasting is less common (18\%) and 29\% of Nigerian children are underweight [3].

Exclusive breastfeeding of an infant involves no food or drink except breast milk, not even water or breastmilk substitute (with the exception of drops or syrups containing vitamins, mineral supplements, or medicine). Evidence from research has shown that breastfeeding remains the best way of feeding an infant in the first six months of life. It meets the full nutritional requirements for healthy full-term infants for the first six months and, in conjunction with complementary foods, provides an essential part of child nutrition into the second year and beyond [6]. Exclusive breast feeding is associated with multiple advantages including child's acquisition of passive immunity against infection, nutrients for physical and mental development, emotional security and closeness to the mother. Breast milk has nutritional, immunological, biochemical, anti-allergic, anti-infective, intellectual, developmental, psychological, psychosocial, economic and environmental benefits for the mother and/or her infant [7] [8]. Majority of the infants are introduced to cereal-based complementary foods well before the recommended 6 months of age [9]. According to a study, one of the reason mothers introduced cereals early to their infants was that they believed that cereals could help their infants sleep longer through the night without disturbing their friends or whoever they were living with [10]. This might also be caused by inadequate breastfeeding facilities provided at workplace. This finding was also being supported in another study which showed that the longer the length of mother's working hours, the less likely the mothers breastfed their children for at least 4 months [11]. In order to understand the effect of maternal employment on feeding practices, this paper examined infant feeding practices vis-a-vis maternal employment in Southwestern Nigeria.

\section{Methodology}

A cross-sectional study was carried out in Osun State, Southwestern Nigeria. The state is located in the south western region of the country and lies within latitude $70^{\circ}$ and $90^{\circ}$ north of equator and longitude $2.75^{\circ}$ and $6.75^{\circ}$ east of Greenish Meridian. A multi stage random sampling procedure was employed. There are thirty Local Government Areas (LGAs) in the state, which is further subdivided into three senatorial districts and each of them has ten LGAs. One third of the senatorial district was selected for this study making a total of nine LGAs from which urban and rural communities were selected. Only 450 mothers of children between the ages of 0 - 24 months were selected, 337 from the urban communities and 113 from the rural communities. Information was sought with the use of structured interview schedule on age of mothers, marital status, years of formal education, number of children, hours worked per day, place of employment, breastfeeding and complementary feeding practices. The research instruments were presented to lecturers, statisticians and nutritionists for critical evaluation, with the objectives and expected outcome of the research taken into consideration.

Height and weight measurements of the children were measured using the standard techniques [12]. Height was measured using a portable measuring unit (Seca Bodymeter Model 208, Seca, Hamburg, Germany) calibrated to the nearest $0.1 \mathrm{~cm}$. Infant height measurement were obtained using a length board. Weight was measured using a digital weighing scale (Model 880, Seca, Hamburg, Germany) calibrated to the nearest $0.1 \mathrm{~kg}$. The Z-scores were calculated using ANTHRO 2005. Children were classified into underweight, stunted or wasted if their weight-for-age (underweight), height-for-age (stunting) and weight for-height (wasting) scores were below -2 standard deviations (SD) of the WHO standards [13]. Data were also analyzed with the SPSS package 16.0. Frequency counts and percentages were used to describe variables and chi square analysis was used to determine difference in maternal characteristics and place of employment. 


\section{Results}

\subsection{Maternal Characteristics}

As presented on Table 1, 55.8\% of children were females while $44.2 \%$ were males. The children between the ages of 0 - 6 months were $33.5 \%$ while $18.7 \%$ were between the ages of 13 - 18 months. Only $48.2 \%$ of mothers were between the ages of 20 - 29, 95.4\% were married and only $4.2 \%$ had no formal education. Mothers had between 1 and 3 children in the family while only $6.6 \%$ had 7 children.

\subsection{Maternal Caring Characteristics}

As presented on Table 2, only $10.4 \%$ of the women were not working while $26.9 \%$ worked at home, $25.3 \%$ worked in the market place, $37.4 \%$ in the factory/office/shop and $46.7 \%$ worked more than 8 hours/day. Only $6.7 \%$ of children of mothers working outside the home were taking care of in the crèche during working hours. Others were in the daycare centres (31.8\%) and at home with other care givers (61.5\%).

Table 1. Frequency and percentage distribution of maternal characteristics.

\begin{tabular}{|c|c|c|c|c|c|c|}
\hline \multirow{2}{*}{ Variables } & \multicolumn{2}{|c|}{ Urban No. $=337$} & \multicolumn{2}{|c|}{ Rural No. = 113} & \multicolumn{2}{|c|}{ Total No. $=450$} \\
\hline & Freq. & $\%$ & Freq. & $\%$ & Freq. & $\%$ \\
\hline \multicolumn{7}{|l|}{ Sex } \\
\hline Male & 145 & 43 & 54 & 47.8 & 199 & 44.2 \\
\hline Female & 192 & 57 & 59 & 52.2 & 251 & 55.8 \\
\hline \multicolumn{7}{|c|}{ Age of children (months) } \\
\hline $0-6$ & 114 & 33.8 & 37 & 32.7 & 150 & 33.5 \\
\hline $7-12$ & 82 & 24.3 & 27 & 23.9 & 111 & 24.8 \\
\hline $13-18$ & 64 & 19.6 & 28 & 18.6 & 84 & 18.7 \\
\hline $19-24$ & 75 & 22.3 & 21 & 24.8 & 103 & 23.0 \\
\hline \multicolumn{7}{|c|}{ Age of mothers (years) } \\
\hline$<20$ & 4 & 1.2 & 4 & 3.5 & 8 & 1.8 \\
\hline $20-29$ & 168 & 49.8 & 49 & 43.4 & 217 & 48.2 \\
\hline $30-39$ & 143 & 42.4 & 46 & 40.7 & 189 & 42 \\
\hline $40-49$ & 19 & 5.6 & 14 & 12.4 & 33 & 7.3 \\
\hline $50-59$ & 3 & 0.9 & 1 & 0.02 & 3 & 0.7 \\
\hline \multicolumn{7}{|l|}{ Marital status } \\
\hline Married & 320 & 95 & 109 & 96.5 & 429 & 95.4 \\
\hline Single & 12 & 3.5 & 1 & 0.9 & 13 & 2.8 \\
\hline Widowed & 5 & 1.5 & 3 & 2.6 & 8 & 1.8 \\
\hline \multicolumn{7}{|c|}{ Years of formal education } \\
\hline None & 19 & 5.6 & 0 & 0.0 & 19 & 4.2 \\
\hline Primary & 77 & 22.8 & 55 & 48.6 & 132 & 29.3 \\
\hline Secondary & 127 & 37.7 & 48 & 42.5 & 175 & 38.8 \\
\hline Tertiary & 111 & 32.9 & 10 & 8.8 & 121 & 26.8 \\
\hline Postgraduate & 03 & 0.9 & 0 & 0.0 & 03 & 0.7 \\
\hline \multicolumn{7}{|c|}{ Number of children } \\
\hline 1 & 86 & 25.5 & 25 & 22.1 & 111 & 24.7 \\
\hline 2 & 92 & 27.2 & 16 & 12.0 & 108 & 24.0 \\
\hline 3 & 88 & 26.1 & 38 & 33.6 & 126 & 22.0 \\
\hline 4 & 45 & 13.4 & 18 & 15.9 & 63 & 14.0 \\
\hline 5 & 17 & 5.0 & 9 & 7.9 & 26 & 5.8 \\
\hline 6 & 7 & 2.1 & 6 & 5.3 & 13 & 2.9 \\
\hline 7 & 2 & 0.7 & 1 & 3.2 & 3 & 6.6 \\
\hline
\end{tabular}


Table 2. Frequency and percentage distribution of maternal caring characteristics.

\begin{tabular}{|c|c|c|c|c|c|c|}
\hline \multirow{2}{*}{ Variables } & \multicolumn{2}{|c|}{ Urban No. = 337} & \multicolumn{2}{|c|}{ Rural No. = 113} & \multicolumn{2}{|c|}{ Total No. $=450$} \\
\hline & Freq. & $\%$ & Freq. & $\%$ & Freq. & $\%$ \\
\hline \multicolumn{7}{|l|}{ Place of employment } \\
\hline Home & 79 & 21.9 & 47 & 41.6 & 121 & 26.9 \\
\hline Market/street & 147 & 23.1 & 35 & 31.0 & 114 & 25.3 \\
\hline Factory/office/shop & 74 & 43.6 & 19 & 16.8 & 168 & 37.4 \\
\hline Not working & 35 & 10.4 & 12 & 10.6 & 47 & 10.4 \\
\hline \multicolumn{7}{|l|}{ Usual hours worked per day } \\
\hline Zero & 47 & 13.9 & 9 & 8.0 & 56 & 12.4 \\
\hline $1-8$ & 140 & 31.1 & 44 & 38.9 & 184 & 40.9 \\
\hline$>8$ & 150 & 45 & 60 & 53.1 & 210 & 46.7 \\
\hline \multicolumn{7}{|l|}{ Hours with children } \\
\hline 1 - 8 hours & $\begin{array}{c}14 \\
92 \\
231\end{array}$ & $\begin{array}{c}4.2 \\
27.3 \\
68.5\end{array}$ & $\begin{array}{c}3 \\
12 \\
98\end{array}$ & $\begin{array}{c}2.7 \\
10.6 \\
86.7\end{array}$ & $\begin{array}{c}17 \\
104 \\
329\end{array}$ & $\begin{array}{c}3.8 \\
23.1 \\
73.1\end{array}$ \\
\hline 9 - 16 hours & 92 & 27.3 & 12 & 10.6 & 104 & 23.1 \\
\hline 17 - 24 hours & 231 & 68.5 & 98 & 86.7 & 329 & 73.1 \\
\hline \multicolumn{7}{|l|}{ Care alternatives } \\
\hline Crèche & 7 & 7.5 & 0 & 0.0 & 7 & 6.7 \\
\hline Daycare & 29 & 31.2 & 4 & 36.4 & 33 & 31.8 \\
\hline Home house help & 57 & 61.3 & 7 & 63.6 & 64 & 61.5 \\
\hline \multicolumn{7}{|c|}{ "Source of information on feeding practices } \\
\hline Health workers & 215 & 64.1 & 67 & 59.3 & 283 & 62.9 \\
\hline Radio & 157 & 46.6 & 46 & 40.7 & 203 & 45.1 \\
\hline Television & 101 & 30.0 & 09 & 8.0 & 110 & 24.4 \\
\hline Older mothers & 102 & 30.3 & 51 & 45.1 & 153 & 34.0 \\
\hline Friends and neighbours & 77 & 22.8 & 37 & 32.7 & 114 & 25.3 \\
\hline Bulletins & 55 & 16.3 & 04 & 3.5 & 55 & 12.2 \\
\hline Magazines & 51 & 15.1 & 05 & 4.4 & 60 & 13.3 \\
\hline
\end{tabular}

\subsection{Infant and Young Child Feeding Practices}

Result on Table 3 revealed that children received prelacteal feeding though $86.4 \%$ of mothers initiated breastfeeding within six hours of birth. Mean number of breastfeeding/day was $9.7 \pm 3.9$ and $23.9 \%$ of children were exclusively breastfed. Mean age of introduction of complementary feeding was $4.4 \pm 2.2$ and mean duration of breastfeeding was $11.9 \pm 7.9$. Only $21.3 \%$ of mothers breastfed their children after the age of 18 months. Mean number of complementary foods/day was $2.7 \pm 1.4$ and snack was $1.7 \pm 0.9$.

\subsection{Place of Employment and Feeding Practices}

The patterns of breastfeeding followed the same pattern irrespective of the place of maternal employment. The number of breastfeeding/day was however higher for mothers working in factories/offices. There existed a 
Table 3. Infant and young child feeding practices.

\begin{tabular}{|c|c|c|c|}
\hline Feeding practices & Urban & Rural & Total \\
\hline \multicolumn{4}{|l|}{ Prelacteal feeding (\%) } \\
\hline Water & 62.9 & 55.8 & $61.1 \%$ \\
\hline Herbs & 27.6 & 53.1 & $34 \%$ \\
\hline Glucose & 35.3 & 22.1 & $32 \%$ \\
\hline Infant formula & 57.3 & 46.9 & $54.7 \%$ \\
\hline Initiation of breastfeeding within six hour of birth (\%) & 88.7 & 81.4 & 86.4 \\
\hline Number of breastfeeding/day (mean and SD) & $11.1 \pm 10.6$ & $8.1 \pm 7.3$ & $9.7 \pm 3.9$ \\
\hline Duration of breastfeeding (mean and SD) & $10.8 \pm 8.0$ & $17.5 \pm 3.6$ & $11.9 \pm 7.9$ \\
\hline Age of introduction of complementary food (mean and SD) & $4.6 \pm 2.1$ & $3.8 \pm 2.4$ & $4.4 \pm 2.2$ \\
\hline \% Exclusive breastfeeding & 35.0 & 6.6 & 23.9 \\
\hline$\%$ Ever breastfed & 100 & 100 & 100 \\
\hline$\%$ Breastfed less than 12 months & 12.9 & 0.0 & 10.1 \\
\hline$\%$ Breastfed up to 12 - 18 months & 67.1 & 73.7 & 68.6 \\
\hline$\%$ Breastfed after 18 months & 20.0 & 26.3 & 21.3 \\
\hline Number of complementary feeding/day (mean and SD) & $2.7 \pm 1.3$ & $2.6 \pm 1.7$ & $2.7 \pm 1.4$ \\
\hline Number of snack/day (mean and SD) & $1.7 \pm 0.9$ & $1.6 \pm 0.9$ & $1.7 \pm 0.9$ \\
\hline
\end{tabular}

significant association between maternal places of employment in the study. It is strongly associated with the timing of introduction of complementary foods $\mathrm{p}<0.02$ and number of snack consumed/day $\mathrm{p}<0.03$ as seen on Table 4.

\section{Discussion}

Young child feeding practices rarely follow the recommendation by WHO. Children as revealed by this study received prelacteal feeding such as water, glucose and infant formula. This is corroborated by a study in Kenya with the prevalence of $26.8 \%$ prelacteal feeds and the most common was infant formula and glucose solution [14]. Glucose is usually given when there is a delay in the let down of milk from the breast while water is mostly given to welcome the baby into the world. All prelacteal feeds are provided for non nutritional reasons such as clearing the throat/bowel; or thinking that mother's milk is insufficient or the colostrum is too heavy for the newborn to digest. Prelacteal feeds have lesser nutrient and immunological value; and are often likely to introduce contaminants [15]. Though most mothers initiated breastfeeding on time, infants received less number of breastfeeding per day, as children received other liquids especially infant formula apart from breast milk. Mothers in the urban communities practice exclusive breastfeeding more than their rural counterpart. Traditional practices of the use of water and concoction is still prevalent in the rural communities as mothers' in-law/grandmothers influences the decision made on the choice of feeding practices. Respondents in the urban centres had higher mean number of breastfeeding compared to their rural counterpart. Complementary foods were introduced before six months at an average of $4.4 \pm 2.2$. This is also revealed in other study with an average age of $4.5 \pm 6.0$. Most mothers do not breastfeed up till the age of 2 years as breastfeeding was terminated between 12 18 months [16]. Mothers in the rural areas however had longer duration of breastfeeding. This is probably because their children are with them most of the time as compared to the urban communities' mothers that have their babies in the crèche or daycare.

The place of employment of mothers may be an important factor in the choice of feeding practices. In this study mothers that worked outside the home had better feeding practices when compared to the non working mothers and those that worked at home. There is a significant difference in the timing of the introduction of the 
Table 4. Chi square analysis of place of employment and feeding practices.

\begin{tabular}{|c|c|c|c|c|c|c|c|c|c|}
\hline \multicolumn{9}{|c|}{ Place of employment } & \multirow[t]{3}{*}{$p$ value } \\
\hline & \multicolumn{2}{|c|}{ Home } & \multicolumn{2}{|c|}{ Market/street } & \multicolumn{2}{|c|}{ Factory/office/shop } & \multicolumn{2}{|c|}{ Not working } & \\
\hline & Freq. & $\%$ & Freq. & $\%$ & Freq. & $\%$ & Freq. & $\%$ & \\
\hline \multicolumn{10}{|c|}{ Exclusive breastfeeding for six months } \\
\hline Yes (95) & 26 & 27.3 & 21 & 22.1 & 37 & 38.9 & 11 & 11.5 & \multirow{2}{*}{0.86} \\
\hline No (355) & 95 & 26.7 & 93 & 26.1 & 131 & 36.9 & 36 & 10.1 & \\
\hline \multicolumn{10}{|c|}{ Number of breastfeeding/day } \\
\hline$<8(75)$ & 16 & 21.3 & 18 & 24 & 36 & 48 & 5 & 6.6 & \multirow{2}{*}{0.32} \\
\hline$>8$ (148) & 33 & 22.2 & 33 & 22.2 & 60 & 40.5 & 22 & 14.8 & \\
\hline \multicolumn{10}{|c|}{ Introduction of complementary food } \\
\hline Before 3 months (54) & 20 & 37.0 & 10 & 18.5 & 18 & 33.3 & 6 & 11.1 & \multirow{3}{*}{$0.02 *$} \\
\hline 3 - 6 months (193) & 40 & 20.7 & 53 & 27.4 & 83 & 43.0 & 17 & 8.8 & \\
\hline$>6$ months $(70)$ & 18 & 25.7 & 20 & 28.5 & 27 & 38.5 & 5 & 7.1 & \\
\hline \multicolumn{10}{|c|}{ Number of complementary foods/day } \\
\hline $1-3(191)$ & 51 & 26.7 & 53 & 27.7 & 65 & 34.0 & 22 & 11.5 & \multirow{2}{*}{0.33} \\
\hline$>3(78)$ & 20 & 25.6 & 21 & 26.9 & 34 & 43.5 & 3 & 3.8 & \\
\hline \multicolumn{10}{|l|}{ Number of snack/day } \\
\hline $0(30)$ & 7 & 23.3 & 11 & 36.6 & 7 & 23.3 & 5 & 16.6 & \multirow{3}{*}{$0.03 *$} \\
\hline $1(45)$ & 8 & 17.7 & 13 & 28.8 & 16 & 35.5 & 8 & 17.7 & \\
\hline$>1(170)$ & 41 & 24.1 & 48 & 28.2 & 70 & 41.1 & 11 & 64.7 & \\
\hline \multicolumn{10}{|c|}{ Termination of breastfeeding } \\
\hline$<12(50)$ & 8 & 16.0 & 14 & 28.0 & 21 & 42.0 & 7 & 14.0 & \multirow{2}{*}{0.14} \\
\hline$>12$ months (68) & 17 & 25.0 & 14 & 20.5 & 24 & 35.2 & 12 & 17.6 & \\
\hline Stunting (262) & 63 & 24.0 & 80 & 30.5 & 93 & 35.5 & 26 & 9.9 & $0.02^{*}$ \\
\hline Wasting (35) & 7 & 20.0 & 10 & 28.6 & 11 & 31.4 & 7 & 20.0 & 0.21 \\
\hline Underweight (107) & 23 & 21.5 & 32 & 29.9 & 35 & 32.7 & 17 & 15.9 & $0.05^{*}$ \\
\hline
\end{tabular}

complementary foods and the number of snack consumed per day. Mothers that worked at home introduced complementary foods earlier that all other groups. Higher proportion of mothers working in the offices/factories introduced complementary foods between 3 - 6 months but offered more complementary feedings per day. These findings are similar to report that employed mothers introduced complementary foods before 6 months [17]. The approved maternity leave in Nigeria is for 3 months after which mother will have to resume working. The decision to introduce complementary food may be influenced by lack of crèches in most working places and the fear of diarrhoea infection from inappropriate hygiene practices by care givers in handling expressed breast milk. It is noted that mothers that worked at home introduce complementary foods earlier than mothers that worked outside the home. Mothers in offices offered more than one snack per day which is one of the approved practices as recommended by WHO. The adoption of appropriate feeding practices therefore is not negatively influenced by maternal occupation and place of work. Maternal occupation influenced feeding practices positively. Mothers that worked in the offices and factories are likely to be educated mothers and may have been influenced in the place of worked and gained knowledge of child care from other nursing mothers. Maternal decisions to breastfeed are influenced by knowledge, support and help with difficulties, not necessarily the place or 
type of job [18]. Working mothers were able to continue breastfeeding in Nairobi [19]. When mothers are aware of the benefit of breastfeeding and the recommended infant and young child feeding practices, trained in lactation management, supported in work place at home, maternal employment will not be a barrier in adopting appropriate practices.

\section{Conclusion}

Appropriate feeding practices by mothers are not negatively influenced by maternal employment. Mothers should be adequately informed about correct practices and should receive support both at home and in work places.

\section{References}

[1] Akuse, R.M. and Obinya, E.A. (2002) Why Healthcare Workers Give Prelacteal Feeds. European Journal of Clinical Nutrition, 56, 729-734. http://dx.doi.org/10.1038/sj.ejcn.1601385

[2] Khanal, V., Adhikari, M., Sauer, K. and Zhao, Y. (2013) Factors Associated with the Introduction of Prelacteal Feeds in Nepal: Findings from the Nepal Demographic and Health Survey 2011. International Breastfeeding Journal, 8, 9. http://dx.doi.org/10.1186/1746-4358-8-9

[3] Nigeria Demographic and Health Survey (NDHS) (2013) National Population Commission Federal Republic of Nigeria Abuja, Nigeria. NPC and ICF Macro, Maryland.

[4] Grzywacz, J.G., Tucker, J., Clinch, C.R. and Arcury, T.A. (2010) Individual and Job-Related Variation in Infant Feeding Practices among Working Mothers. American Journal of Health Behavior, 34, 186-196. http://dx.doi.org/10.5993/AJHB.34.2.6

[5] Dili (2008) Behavior Change Communication Strategy for Child Health. East African Journal of Public Health, 7, 258262.

[6] WHO (2009) Global Strategy for Infant and Young Child Feeding (IYCF) Model Chapter for Text Books for Medical Students and Allied Health Professionals. World Health Organization, Switzerland.

[7] Earle, S. (2002) Factors Affecting the Initiation of Breast-Feeding: Implications for Breast-Feeding Promotion. Health Promotion International, 17, 205-214. http://dx.doi.org/10.1093/heapro/17.3.205

[8] Lawrence, N., Hand, I., Haynes, D., McVeigh, T., MaeHee, K. and Ja Yoon, J. (2003) Factors Influencing Initiation of Breastfeeding among Urban Women. American Journal of Perinatology, 20, 477-483. http://dx.doi.org/10.1055/s-2003-814732

[9] Onyango, A.W. (2003) Dietary Diversity, Child Nutrition and Health in Contemporary African Communities. Comparative Biochemistry and Physiology Part A: Molecular \& Integrative Physiology, 136, 61-69. http://dx.doi.org/10.1016/S1095-6433(03)00071-0

[10] Olson, B.H., Horodynski, M.A., Brophy-Herb, H. and Iwanski, K.C. (2010) Health Professionals’ Perspectives on the Infant Feeding Practices of Low Income Mothers. Maternal and Child Health Journal, 14, 75-85. http://dx.doi.org/10.1007/s10995-008-0425-2

[11] Hawkins, S.S., Griffiths, L.J., Dezateux, C. and Law, C. (2007) The Impact of Maternal Employment on Breast-Feeding Duration in the UK Millenium Cohort Study. Public Health Nutrition, 10, 891-896. http://dx.doi.org/10.1017/S1368980007226096

[12] Gibson, R. (2005) Principles of Nutritional Assessment. 2nd Edition, Oxford University Press, New York, 41-64.

[13] World Health Organization, Multicentre Growth Reference Study Group (2006) WHO Child Growth Standards: Methods and Development: Length/Height-for-Age, Weight-for-Age, Weight-for-Length, Weight-for-Height and Body Mass Index-for-Age. World Health Organization, Geneva.

[14] Lakati, A.S., Makokha, O.A., Binns, C.W. and Kombe, Y. (2010) The Effect of Pre-Lacteal Feeding on Full Breastfeeding in Nairobi, Kenya. East African Journal of Public Health, 7, 258-262.

[15] Laroia, N. and Sharma, D. (2006) The Religious and Cultural Bases for Breastfeeding Practices among the Hindus. Breastfeeding Medicine, 1, 94-98. http://dx.doi.org/10.1089/bfm.2006.1.94

[16] Sellen, D.W. (2001) Comparison of Infant Feeding Patterns Reported for Nonindustrial Populations with Current Recommendations. Journal of Nutrition, 131, 2707-2715.

[17] Farhanah, S. and Naleena, D.M. (2012) The Association of Maternal Employment Status on Nutritional Status among Children in Selected Kindergartens in Selangor, Malaysia. Asian Journal of Clinical Nutrition, 4, 53-66. http://dx.doi.org/10.3923/ajcn.2012.53.66

[18] Brown, A., Raynor, P. and Lee, M. (2011) Healthcare Professionals’ and Mothers’ Perceptions of Factors That Influ- 
ence Decisions to Breastfeed or Formula Feed Infants: A Comparative Study. Journal of Advanced Nursing, 67, 19932003. http://dx.doi.org/10.1111/j.1365-2648.2011.05647.x

[19] Lakati, A., Binns, C. and Stevenson, M. (2002) The Effect of Work Status on Exclusive Breastfeeding in Nairobi. AsiaPacific Journal of Public Health, 14, 85-90. http://dx.doi.org/10.1177/101053950201400206 